\title{
Pharmacological approaches to reducing blood loss and transfusions in the surgical patient
}

\author{
[Approches pharmacologiques de réduction des pertes sanguines et des transfusions \\ en chirurgie]
}

Yves Ozier MD, * Sylvie Schlumberger MD $\dagger$

Purpose: To review the efficacy, effectiveness and safety of hemostatic drugs to reduce surgical blood loss.

Methods: Analysis of randomized controlled trials and metaanalyses exploring the efficacy of desmopressin, aprotinin, lysine analogues and recombinant activated factor VII (rFVlla) on clinically important endpoints.

Main findings: Although potentially useful in surgical patients with mild hemophilia or type I von Willebrand's disease, desmopressin has no proven benefit in patients without previous hemostatic defects. Aprotinin has been studied extensively in cardiopulmonary bypass surgery, with evidence of a blood sparing effect. Additional benefits are suggested. The drug is less consistently effective in liver transplantation and major orthopedic surgery. Although rare, hypersensitivity reactions to aprotinin may occur, especially on re-exposure. Tranexamic acid can reduce blood transfusion in cardiac surgery, liver transplantation and total knee arthroplasty surgery with a satisfactory safety profile. Epsilon aminocaproic acid has not been investigated adequately, despite its widespread use. While rFVIla may be beneficial in controlling massive coagulopathic bleeding in trauma and surgical patients, there is currently no evidence to support its prophylactic use in elective surgical patients.

Conclusion: Aprotinin and tranexamic acid are valuable pharmacologic options for reducing surgical bleeding. The expected benefit of these drugs is highly dependent on the actual blood usage for a given procedure at the institutional level. More studies using clinically significant endpoints are necessary to assess the relative efficacy and optimal dosing of these drugs.

Objectif : Revoir l'efficacité, l'activité et la sécurité des médicaments hémostatiques pour réduire les pertes sanguines chirurgicales.

Méthode : Nous avons fait une analyse des études randomisées et contrôlées et des méta-analyses qui explorent l'efficacité de la desmopressine, de l'aprotinine, des analogues de la lysine et du facteur VII recombinant activé (rFVIIa) sur les paramètres cliniques importants.

Constatations principales: La desmopressine, potentiellement utile chez les patients de chirurgie atteints d'hémophilie bénigne ou de la maladie de von Willebrand de type I, n'a pas été prouvée avantageuse chez les patients sans défauts hémostatiques antérieurs. L'aprotinine a été beaucoup étudiée en chirurgie sous circulation extracorporelle et a révélé son effet hémostatique. Des bienfaits additionnels sont évoqués. Le médicament présente un effet moins constant pour la transplantation hépatique et la chirurgie orthopédique majeure. Quoique rares, des réactions d'hypersensibilité à l'aprotinine peuvent survenir, surtout lors d'une réexposition. L'acide tranexamique peut réduire la transfusion sanguine en chirurgie cardiaque, pendant la transplantation hépatique et l'arthroplastie totale du genou, selon un profil d'innocuité satisfaisant. L'acide epsilon amino-caproïque n'a pas été suffisamment exploré, malgré son usage très répandu. Tandis que le rFVIla peut être bénéfique pour contrôler le saignement coagulopathique massif en chirurgie et chez les polytraumatisés, il n'y a pas de preuve actuellement pour appuyer son usage prophylactique en chirurgie réglée.

Conclusion: L'aprotinine et l'acide tranexamique sont valables pour réduire le saignement chirurgical. L'avantage attendu de ces médicaments dépend beaucoup de l'usage réel de sang pour une intervention donnée au niveau institutionnel. D'autres études de paramètres cliniques significatifs nous feraient connaître l'efficacité relative et le dosage optimal de ces médicaments.

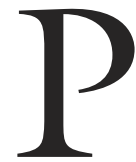
HARMACOLOGICAL therapies to reduce blood loss in surgery may be classified in two categories: drugs that decrease intravascular hydrostatic pressures and drugs that act on hemostasis, coagulation and/or fibrinolysis. This review will focus on the latter group, including desmo-

From the Service d'Anesthésie-Réanimation Chirurgicale, ${ }^{*}$ Assistance Publique-Hôpitaux de Paris, Hôpital Cochin; Université René Descartes Paris 5, Fac Med; and the Department of Anesthesia, † Hôpital Foch, Paris, France.

Address correspondence to: Dr. Yves Ozier, Department of Anesthesia and Intensive Care, Groupe Hospitalier Cochin, 27, rue du Fbg Saint-Jacques, F-75629 Paris, France. Phone: 3315841 16 87; Fax: 3315841 14 15; E-mail: yves.ozier@cch.aphp.fr 
pressin acetate, aprotinin, lysine analogues and recombinant activated factor VII (rFVIIa). Basic mechanisms of action, pharmacological properties, dosing, efficacy and adverse reactions will be considered.

To understand and interpret the large number of studies performed on the use of hemostatic agents in surgery, two major issues need to be considered:

- The measured outcome is an important methological issue. The ultimate goal of using such drugs is to decrease morbidity and mortality related to surgical bleeding. A lower rate of re-operation for surgical hemostasis is another interesting objective, due to its consistent link with mortality. A decrease in blood transfusion requirements remains, nevertheless, a clinically and economically significant endpoint. Conversely, a decrease in blood loss per se and/or an improvement in laboratory coagulation tests cannot be considered acceptable surrogate markers.

- Owing to differences in surgical blood loss and/ or transfusion triggers, blood component usage differs markedly among institutions for the same type of surgical procedure. A benefit observed with a hemostatic drug in one institution should, therefore, be extrapolated to another institution with caution.

\section{1.- DESMOPRESSIN}

Desmopressin (1-deamino-8-D-arginine vasopressin or dDAVP) is a synthetic analogue of vasopressin that was initially devoted to the treatment of central diabetes insipidus. Intravenous administration of desmopressin raises factor VIII and von Willebrand factor plasma concentrations in healthy volunteers. The increase is related to a release from endothelial intracellular storage pools and not to de novo synthesis. Therefore, this effect is rapid, transient, and diminishes with repeated injections at short intervals. This agent also transiently increases tissue plasminogen activator ( $\mathrm{t}-\mathrm{PA})$ and prostacyclin plasma levels. Additional effects on hemostasis cannot be excluded.

\section{1.- Clinical use and efficiency}

Desmopressin has been used successfully in the prevention or treatment of bleeding due to minor surgical procedures in mild hemophilia A and type I von Willebrand's disease. Desmopressin is also efficacious for indications not involving FVIII and von Willebrand factor. Notably, it shortens the bleeding time in patients with certain acquired platelet function disorders (chronic renal failure, acetyl-salicylic acid intake). The usual dose is $0.3 \mu \mathrm{g} \cdot \mathrm{kg}^{-1} i v$, and the infusion should continued for at least $20 \mathrm{~min}$.

Desmopressin has been used as a hemostatic agent in patients without pre-existing bleeding disorders undergoing major surgery, mainly cardiac or spinal procedures.

\subsection{1.- Cardiac surgery with cardiopulmonary bypass $(C P B)$}

Cardiopulmonary bypass leads to alterations in platelet function. The hypothesis that desmopressin may be helpful has been supported by results of initial trials. However, later studies challenged this view. Two metaanalyses have focused on the efficacy of pharmaceutical agents on blood transfusion in cardiac surgery. The former, performed by the International Study group of Peri-Operative Transfusion (ISPOT), concluded that desmopressin had no significant influence on the proportion of transfused patients. ${ }^{1}$ The latter concluded that desmopressin did not influence mortality, the rate of re-operation for hemostasis and the proportion of transfused patients. ${ }^{2}$ However, the ISPOT meta-analysis suggested that patients taking aspirin may benefit from desmopressin, but this is uncertain. ${ }^{1}$

\subsection{2.- Non cardiac surgery}

Why desmopressin may reduce blood loss in noncardiac surgery is not clear, but this effect has been studied extensively in spinal procedures. The prophylactic administration of desmopressin was found effective in reducing blood transfusions in earlier studies, but not in the most recent randomized controlled trials (RCTs). ${ }^{3}$ Similarly, a recent RCT in liver resections did not result in any beneficial effect of desmopressin. ${ }^{4}$

\section{2.- Safety}

Adverse effects usually include a mild and transient systemic arterial hypotension and tachycardia that may be related to the endothelial release of prostacycline and/or nitric oxide in the circulation. Water retention rarely leads to significant hyponatremia in adults, but should be considered in young children. In the ISPOT meta-analysis in $\mathrm{CPB}$ surgery, perioperative myocardial infarctions tended to be more frequent in desmopressin-treated patients than in the placebo group (4.4\% vs $1.6 \%) .{ }^{1} \mathrm{~A} 2.4$-fold, significant increase in the risk of myocardial infarction was also found in the Dutch meta-analysis. ${ }^{2}$ Therefore, dDAVP should be used with caution in patients with arterial and coronary artery disease.

In summary, convincing evidence that desmopressin is efficacious in reducing blood loss in several surgical procedures is still lacking, although a beneficial effect cannot be excluded in a subgroup of cardiac surgery patients which remains to be determined. A potential increase in the rate of myocardial infarctions must be considered. 


\section{2.- APROTININ}

Aprotinin is a small, alkaline polypeptide $(6.5 \mathrm{kD})$. It is extracted from bovine tissues but can be produced genetically. Aprotinin belongs to the SERine-Proteases INhibitors (SERPINS) family and can neutralize a wide-spectrum of biological systems, notably trypsin, plasmin, and tissue and plasma kallikrein. Biological activity is commonly expressed as kallikrein inhibiting units (KIU) where $106 \mathrm{KIU}$ are equivalent to $140 \mathrm{mg}$ or $21 \mu \mathrm{mol}$ of the compound. The biological effects of aprotinin are postulated to depend on its plasma concentration and the target proteases to be inhibited. Data from in vitro experiments indicate that plasma concentrations inhibiting trypsin, plasmin, tissue kallikrein, plasma kallikrein and thrombin are, respectively, 25, 50, 125, 200 et $600 \mathrm{UIK} \cdot \mathrm{mL}^{-1}$. Due to the antiplasmin activity obtained at rather low concentrations, aprotinin is often seen as an antifibrinolytic agent. However, its biological activities are more complex. Studies in CPB surgery have shown that its use is associated with decreased markers of coagulation activation (prothrombin fragments $1+2$, thrombin-antithrombin complexes). The mechanisms by which aprotinin improves hemostasis are not entirely understood. Major hypotheses include the inhibition of fibrinolysis, the preservation of platelet function and inhibition of the contact phase of coagulation. In addition, high doses of aprotinin may, potentially, decrease the acute inflammatory response to $\mathrm{CPB}$, but the clinical relevance of this effect remains unclear. Recently, it has been shown that aprotinin can block activation of the platelet protease-activated receptor-l (PAR-1) by thrombin. ${ }^{5}$ This blockade of thrombininduced platelet activation does not prevent platelet aggregation in response to collagen and the hemostatic capacity of platelets in surgical wounds. However, it suggests that aprotinin could have anti-thrombotic properties.

The pharmacokinetics of aprotinin appear more complex than thought previously, and have been compared to those of heparin. After a single iv injection, aprotinin undergoes a rapid redistribution from the plasma through binding to the endothelium. Even with a weight-adjusted dosing scheme, there is a wide inter-individual variability in the time-plasma concentration curves of aprotinin in CPB surgery. In patients with renal failure, aprotinin clearance is reduced and the half-life is prolonged.

\section{1.- Clinical use and efficacy}

Aprotinin has been used in various types of operations, mainly cardiac, hepatic and orthopedic surgery. There are limited data on its use in postpartum hemorrhage and traumatic injury. ${ }^{6}$ Neither the optimal dose of aprotinin nor the appropriate therapeutic concentrations required for effective hemostasis have been established definitively. As a consequence, many different dosing regimens have been used. The classical "Full Hammersmith regimen" calls for an initial dose of $2 \times 10^{6} \mathrm{KIU}(280 \mathrm{mg})$ followed by a maintenance infusion of $500,000 \mathrm{KIU} \cdot \mathrm{hr}^{-1}\left(70 \mathrm{mg} \cdot \mathrm{hr}^{-1}\right)$, with another $2 \times 10^{6} \mathrm{KIU}$ added to the $\mathrm{CPB}$ pump prime solution. This dosing regimen attempts to maintain a plasma aprotinin concentration sufficient to inhibit kallikrein during $\mathrm{CPB}$. Higher doses $\left(6 \times 10^{6} \mathrm{KIU}\right)$, several lower dose regimens, "pump-prime" of the $\mathrm{CPB}$, and topical application on the surgical wound have also been evaluated.

\subsection{1.- Cardiopulmonary bypass surgery}

Aprotinin has been studied extensively in CPB surgery. A large number of trials consistently show that aprotinin can reduce blood loss and blood transfusion in this setting. The authors of a recent meta-analysis concluded that there is no need for further placebocontrolled trials of this agent in cardiac surgery. ${ }^{7}$ In the meta-analysis by Levi et al. in 1999, treatment with aprotinin decreased the proportion of patients transfused (from $63 \%$ to $43 \%$ ) and of patients requiring rethoracotomy (from $5.0 \%$ to $1.8 \%$ ). ${ }^{2}$ In this metaanalysis, mortality was decreased by almost twofold. Marked heterogeneity in the magnitude of the bloodsparing effect (but not in the re-operation rate) has been stressed. 7 Two major factors appear to influence efficacy: a) higher doses tend to be more efficacious than lower doses; and b) limited blood saving has been found in some centres with a restrictive transfusion policy. Transfusion threshold is a major source of heterogeneity when comparing trial outcomes. A low transfusion rate in the control group is an obvious limit to the potential benefit of any blood-sparing strategy.

\subsection{2.- Liver surgery}

As hyperfibrinolysis may be encountered in orthotopic liver transplantation, the use of antifibrinolytic agents to reduce blood loss has been evaluated in these patients. In the early 1990s, several non randomized studies with historical controls were published by different European centres using aprotinin prophylactically, in a manner very similar to the Hammersmith regimen used in cardiac surgery $\left(2 \times 10^{6} \mathrm{KIU}\right.$ initial dose and $0.5 \times 10^{6} \mathrm{KIU} \cdot \mathrm{hr}^{-1}$ infusion). These uncontrolled trials showed impressive results and opened interesting perspectives. However, initial RCTs failed to demonstrate a significant difference in blood transfusion between aprotinin treated and control patients. ${ }^{89}$ Recently, a 
European multicentre placebo-controlled randomized study (EMSALT study) tested the efficacy of a "plasmin inhibiting" dose and of a "kallikrein inhibiting" dose of aprotinin. ${ }^{10}$ The median number of allogeneic and autologous blood units transfused was decreased significantly by aprotinin $(37 \%$ reduction in the high-dose group and $20 \%$ reduction in the lowdose group). ${ }^{10}$ These inconsistent results suggest that aprotinin's effectiveness may be impacted by specific surgical considerations and/or institutional transfusion policies. Even if aprotinin is used widely in many liver transplant centres in Europe, the most appropriate regimen remains a subject of debate.

Other benefits of aprotinin administration in liver transplantation have been reported: more stable hemodynamic state, less need for vasoactive agents, and even improved one-month graft survival. Whether these observations result from decreased bleeding or from other effects of aprotinin remains speculative.

\subsection{3.- Orthopedic surgery}

Several RCTs suggest that aprotinin can reduce blood requirements in major orthopedic surgery. Major reductions in blood use have been observed in patients with bone tumours and/or septic surgery, although this is not a universal finding. ${ }^{1-13}$ As a general rule, the blood sparing efficacy is significant in situations or centres with heavy blood consumption in the control group whereas the benefit is modest, if any, in patient groups at low risk of bleeding and transfusion. Similarly, trials have been performed in total hip or knee replacement patients with inconsistent results.

\section{2.- Safety}

Three types of adverse events have been reported:

\subsection{1.- Hypersensitivity-type reactions}

Because aprotinin is a foreign polypeptide extracted from bovine lung, hypersensitivity type reactions are of significant concern. There are numerous reports of severe anaphylactic reactions to aprotinin, especially on re-exposure. Severe reactions have also been reported on initial aprotinin administration, on a 1 $\mathrm{mL}$ test dose $(10,000 \mathrm{KIU})$, and in patients treated topically with fibrin sealants containing aprotinin. ${ }^{14}$ Dietrich et al. found the incidence of allergic reactions after aprotinin re-exposure during cardiac surgery to be $2.5 \%{ }^{15}$ Severe allergic reactions to aprotinin are more likely to occur if the length of the exposure/reexposure interval is shorter than six months.

There is no reliable prophylaxis against allergic reactions to aprotinin, but some preventive measures have been suggested. Re-exposure to aprotinin within the first six months after the previous exposure should be avoided. However, a negative exposure history does not exclude the possibility of an allergic reaction. The possibility of an allergic reaction must therefore be kept in mind whenever this agent is used. The $1-\mathrm{mL}$ test dose before any exposure, suggested by the manufacturer, can lead to severe reactions. Delaying the test dose until cannulation sites for $\mathrm{CPB}$ are exposed has been advised. A preoperative skin prick test is not predictive of the response to aprotinin. Detectable aprotinin-specific $\operatorname{IgG}$ or $\operatorname{IgE}$ antibodies lack specificity to identify patients at risk for developing an anaphylactic reaction upon re-exposure, although high concentrations of anti aprotinin IgG antibodies may help. ${ }^{15}$

\subsection{2.- Thrombotic potential}

Concerns have been expressed regarding a prothrombotic effect of this agent. Whether aprotinin may influence early graft occlusion rate after coronary artery bypass surgery has, especially, been debated. The International Multicenter Graft Patency Experience (IMAGE) trial examined the effects of aprotinin on graft patency and incidence of myocardial infarction in patients undergoing primary coronary artery bypass graft operations with CPB. ${ }^{16}$ More than 800 patients were included at 13 international sites in this RCT. Among 703 patients with assessable saphenous vein grafts, occlusions occurred in $15.4 \%$ of aprotinintreated patients and $10.9 \%$ of patients given placebo $(P=0.03)$. However, the authors adjusted for risk factors associated with vein graft occlusion and found that the aprotinin $v s$ placebo risk ratio decreased from 1.7 to 1.05 (90\% confidence interval, 0.6 to 1.8 ). Aprotinin did not affect the occurrence of definite myocardial infarction or mortality. The conclusion of the trial is that the probability of early vein graft occlusion is increased by aprotinin when other risk factors for graft occlusion are present. ${ }^{16}$ However, no increase in myocardial infarction, stroke, deep vein thrombosis, pulmonary embolism has been substantiated by the results of the Cochrane group meta-analysis. ${ }^{7}$ No increase in the risk of liver graft vasculature thrombosis has been documented either. Conversely, there are data indicating a decrease in the incidence of perioperative stroke in $\mathrm{CPB}$ surgery. ${ }^{17}$ The recent demonstration of an inhibition of thrombin-induced platelet activation via PAR-1 blockade has fueled speculations about an antithrombotic potential of aprotinin. ${ }^{5}$

In contrast, the recently published conclusions of an observational study involving 4,374 patients undergoing cardiac revascularization in 69 institutions located in sixteen countries (of whom 1,295 patients received aprotinin) raised safety concerns with regards to apro- 
tinin. ${ }^{18}$ Using propensity and multivariate methods, it was found that use of aprotinin was associated with a significant increase in the risk of myocardial infarction or heart failure [OR $1.42(1.09-1.86)]$ and in the risk of stroke or encephalopathy [OR 2.15 (1.14 $-4.06)$ ] among patients undergoing primary surgery. ${ }^{18}$ Interestingly, this association was not significant for complex surgery (primary surgery = elective surgery involving only myocardial revascularization with cardiopulmonary bypass; complex surgery $=$ all others $).{ }^{18}$ In view of such inconsistent safety data and until further information becomes available (notably coming from the ongoing Canadian study "Blood conservation using Antifibrinolytics: a Randomized Trial in a cardiac surgery population - BART"), we suggest avoiding aprotinin in primary revascularization surgery, and to limit its use to complex cardiac surgery and to urgent cardiac operations in patients taking clopidogrel.

\subsection{3.- Miscellaneous}

In the early 1990s, an increased risk of renal failure was reported with the use of aprotinin in elderly patients undergoing operations on the thoracic or thoracoabdominal aorta using $\mathrm{CPB}$ and hypothermic circulatory arrest. However, later studies in patients treated with deep hypothermic circulatory arrest did not confirm this association. Aprotinin does not increase the likelihood of renal dysfunction in liver transplant recipients. ${ }^{19}$ Schweizer et al. compared high dose aprotinin with a placebo with regard to renal hemodynamics and function in cardiac surgery and could not find any alterations. ${ }^{20}$ However, other investigators observed that aprotinin could increase tubular markers of renal dysfunction. Contrary to the reassuring results of meta-analyses ${ }^{7}$ having examined this point, the observational study by Mangano et al. concluded that the use of aprotinin was associated with an increased risk of renal failure requiring dialysis among patients requiring primary surgery (OR 2.34 [1.27 to 4.31$])$ or complex coronary artery surgery (OR 2.59 [ 1.36 to 4.95$]$ ). ${ }^{18}$ Until further information becomes available, it appears prudent to avoid the use of aprotinin in patients with significant preoperative renal dysfunction.

Finally, concerns about the bovine origin of the drug have been raised, especially in European countries, leading to the development of recombinant aprotinin, as for other hemostatic agents used to treat disturbances of hemostasis.

\section{3.- LYSINE ANALOGUES}

This group of drugs includes epsilon-aminocaproic acid (EACA) and tranexamic acid (TxA). These syn- thetic derivatives of the amino-acid lysine competitively block the lysine binding sites of the plasminogen molecule. They, therefore, prevent the formation of a ternary complex with t-PA and fibrin and inhibit fibrinolysis. These agents share common characteristics: low molecular weight, hydrophilia, renal elimination with little/no biotransformation, and low cost. Tranexamic acid is six to ten times more potent in vitro and has a longer elimination half-life than EACA (approximately two hours after a single $i v$ dose).

\section{1.- Clinical use and efficacy}

For many years, synthetic antifibrinolytics have been used as an adjunct therapy/prophylaxis of bleeding in various indications (oral surgery in patients with coagulation abnormalities, menorrhagia). They are used mainly to reduce blood loss and transfusion in $\mathrm{CPB}$ surgery and liver transplantation. A wide range of empirical dosage regimens have been used. The usual administration route is $i v$, but TxA is available in oral form. In some countries, EACA is not available anymore. In general, TxA has been investigated more thoroughly than EACA.

\subsection{1.- Cardiopulmonary bypass surgery \\ - EPSILON-AMINOCAPROIC ACID}

Epsilon-aminocaproic acid has been used in cardiac surgery since the 1960s to decrease postoperative blood loss, with a few studies showing some efficacy. The efficacy of EACA is similar whether the agent is administered prior to incision or following heparinization. $^{21}$ Its potential to reduce blood product requirements is however inconsistent, and the reduction in red blood cell (RBC) transfusion was not statistically significant in a recent meta-analysis. ${ }^{7}$

- TRANEXAMIC ACID

The prophylactic regimen (dose, timing, and method of administration) of TxA to reduce blood loss associated with CPB surgery has varied greatly between studies, ranging from a $150 \mathrm{mg} \cdot \mathrm{kg}^{-1}$ initial single bolus dose to a $10 \mathrm{mg} \cdot \mathrm{kg}^{-1}$ initial dose followed by a $1 \mathrm{mg} \cdot \mathrm{kg}^{-1} \cdot \mathrm{hr}^{-1}$ infusion. Dowd et al. have shown that TxA is eliminated rapidly by patients undergoing $\mathrm{CPB}$ surgery when given as a single bolus dose. High-dose TxA (50 mg. $\mathrm{kg}^{-1}$ and $100 \mathrm{mg} \cdot \mathrm{kg}^{-1}$ ) was associated with higher peak plasma concentrations than low-dose TA $\left(10 \mathrm{mg} \cdot \mathrm{kg}^{-1}+\right.$ $1 \mathrm{mg} \cdot \mathrm{kg}^{-1} \cdot \mathrm{hr}^{-1}$ for ten hours) and maintained longer steady concentration within a theoretically assumed therapeutic range. ${ }^{22}$ Impaired renal function is expected to result in higher plasma concentrations after CPB. ${ }^{23}$

Although blood loss is reduced in most studies, the improvement in blood transfusion is inconsistent. 
This heterogeneity may be due to different dosing schedules or to a relatively low blood transfusion rate in the placebo group, limiting the potential benefit of TxA in some trials. A meta-analysis of 15 randomized trials including 1,151 patients concluded that the use of TxA significantly decreases the rate of allogeneic blood exposure in cardiac surgery by $29 \% .^{7}$ The relative risk of re-operation for bleeding was also significantly lower. ${ }^{2}$ The amount of blood saved averaged one unit.

\subsection{2.- Liver transplantation}

Clinical experience with EACA in liver transplantation was initiated by Kang et al. ${ }^{24}$ In 20 out of 97 orthotopic liver transplant recipients, the authors observed a hyperfibrinolytic state with severe oozing that could be treated effectively with a single $\mathrm{lg}$ bolus of EACA. ${ }^{24}$ Despite being the oldest drug used to treat hyperfibrinolysis in liver transplantation, prophylaxis with EACA has not been studied extensively. In one study, EACA (continuous infusion at a rate of $16 \mathrm{mg} \cdot \mathrm{kg}^{-1} \cdot \mathrm{hr}^{-1}$ ) was compared to TxA (continuous infusion at a rate of $\left.10 \mathrm{mg} \cdot \mathrm{kg}^{-1} \cdot \mathrm{hr}^{-1}\right)$ and placebo. ${ }^{25}$ Epsilon-aminocaproic acid was not found to be more effective than placebo, whereas TxA significantly reduced the amount of $\mathrm{RBC}$ units and the proportion of patients transfused. ${ }^{25} \mathrm{~A}$ blood sparing effect of TxA was also reported by Boylan et al. who used a higher dose $\left(40 \mathrm{mg} \cdot \mathrm{kg}^{-1} \cdot \mathrm{hr}^{-1}\right) \cdot{ }^{26}$ In contrast, Kaspar et al. did not find any reduction in transfusion requirements with TxA, although the incidence of fibrinolysis decreased. However, in the latter study, a small dose of TA $\left(2 \mathrm{mg} \cdot \mathrm{kg}^{-1} \cdot \mathrm{hr}^{-1}\right)$ was used, and blood requirements were low in the placebo group. ${ }^{27}$

\subsection{3.- Orthopedic surgery}

The performance of TxA has been studied mostly in total knee replacement surgery, as the use of a tourniquet is assumed to increase fibrinolysis, potentially contributing to delayed bleeding. A number of randomized studies have reported reduced postoperative blood losses and transfusions after TxA administration $^{28-30}$ and a recent meta-analysis concluded that TxA is effective in reducing the requirements for allogeneic blood in this type of procedure. ${ }^{31}$ Various dosing regimens have been used, including pre and postoperative oral administration. ${ }^{30}$ Tranexamic acid has also been used successfully to reduce blood transfusions in secondary scoliosis surgery. ${ }^{32}$

\section{2.- Safety}

Since lysine analogues inhibit fibrinolysis without suppressing thrombin generation, concerns have been raised regarding their prothrombotic potential. Case reports have described excessive clot formation on pulmonary artery catheters in non heparinized patients receiving EACA. In CPB surgery, infusion after systemic heparinization and through a peripheral venous catheter have been recommended. ${ }^{33}$ As for aprotinin, the possibility of a causative link between fatal intraoperative thromboembolism and EACA administration in a few liver transplant recipients has been raised. However, this concern has not been substantiated by the results of controlled trials or meta-analyses. ${ }^{7}$ No increase in the rate of myocardial infarction, stroke, deep vein thrombosis, pulmonary embolism or thrombosis of the liver graft vasculature has been documented.

Another safety concern is the broad range of renal complications attributed to EACA (acute tubular necrosis, myoglobin-induced renal failure, glomerular capillary thrombosis, obstruction of the upper urinary tract). Many of those complications have been reported following prolonged use and/or high doses. The nephrotoxic potential of moderate EACA doses ( $10 \mathrm{~g}$ iv bolus prior to $\mathrm{CPB}$, followed by $\mathrm{l} \mathrm{g} \cdot \mathrm{hr}^{-1}$ for five hours) in elective primary coronary bypass surgery patients has been studied retrospectively using perioperative changes in creatinine clearance. ${ }^{34}$ No relationship could be established between postoperative reductions in creatinine clearance and EACA administration. ${ }^{34}$ It can be concluded that moderate doses of EACA do not result in clinically significant harm to the kidney in this setting, although minor renal toxicity cannot be excluded.

\section{3.- Lysine analogues or aprotinin?}

In cardiac surgery, a few studies with a small sample size have compared aprotinin directly with TxA for the reduction of transfusion requirements. The Cochrane group meta-analysis found the blood-sparing effect of both drugs to be similar, with a trend favouring aprotinin. ${ }^{7}$ Recently, one study found aprotinin to be more effective than TxA. ${ }^{35}$ A "head-to-head" RCT in liver transplantation failed to demonstrate a difference between TxA and aprotinin regarding blood use. ${ }^{36}$ Thus, at present, comparative data on clinical efficacy are insufficient to suggest an agent of choice.

Lysine-analogues are much cheaper than aprotinin and seem to be devoid of allergic reactions. Due to its low cost and lack of sensitization, TxA is often preferred in low risk primary cardiac surgery, while aprotinin is reserved for more complex or revision cardiac procedures and patients receiving clopidogrel who require urgent surgery. 


\section{4.- RECOMBINANT FACTOR VIIa}

Recombinant factor VIIa (eptacog alpha activated, Novoseven ${ }^{\circledR}$ in Europe, Niastase ${ }^{\circledR}$ in North America) has been introduced and approved for the treatment of hemophilia patients with inhibitors, either in surgical or non-surgical situations. Wider applications of rFVIIa are under development.

This agent is produced from a baby hamster cell line and is very similar to endogenous FVIIa. Experimental data indicate that high doses of rFVIIa enhance thrombin generation through both tissue factor-dependent and tissue factor-independent pathways. Pharmacological concentrations of rFVIIa may enhance thrombin formation on activated platelets accumulated at the site of vascular damage. The agent seems to be well tolerated, and has a short half-life (approximately $2.7 \mathrm{hr}$ for an initial dose in adults) which may be reduced in massively bleeding patients. ${ }^{37} \mathrm{~A}$ widespread activation of coagulation resulting in disseminated intravascular coagulation has not been observed. Thromboembolic events are rare in hemophilia patients but have been reported more frequently in patients with a normal baseline hemostatic function.

A growing number of case reports and case series suggest that this potent hemostatic agent may be effective in various "off-label" indications. ${ }^{38}$ The compound has been found effective in controlling intractable bleeding in trauma, ${ }^{39}$ obstetrical ${ }^{40}$ and surgical patients with complex acquired coagulation abnormalities. Efficacy is usually appreciated through the response to rFVIIa in terms of amount of RBC units required before and after administration of the drug. A recent multicentre, randomized, doubleblind, placebo controlled study has shown that rFVIIa was effective in reducing RBC transfusions (mean decrease of $2.6 \mathrm{U}$ ) and massive transfusions in the subgroup of patients with blunt trauma who survived more than $48 \mathrm{hr}^{41}$

Besides such rescue therapeutic experiences with rFVIIa in disastrous situations, its use to prevent heavy blood loss in defined surgical situations (complex cardiac surgery, liver transplantation) has been explored. The hypothesis that the prophylactic use of rFVIIa can reduce perioperative bleeding in patients without preexisting coagulation defects has been supported by a randomized placebo-controlled trial in patients undergoing retro-pubic prostatectomy. ${ }^{42}$ However, other clinical trials have not shown any efficacy of rFVIIa in preventing surgical bleeding. ${ }^{43-45}$ Whereas this interesting hemostatic agent definitely appears promising to treat life-threatening, uncontrolled bleeding resulting from complex coagulopathies secondary to trauma or surgery, one can really question the prophylactic use of such an expensive drug to reduce the probability of receiving one or two blood units. Finally, one should keep in mind that a history of thromboembolic events (deep vein thrombosis, pulmonary embolus, cerebrovascular accident, etc.) was a strict exclusion criterion in all RCTs involving rFVIIa, limiting the generalizability of the results.

\section{Conclusion}

The hemostatic benefits of aprotinin and TxA acid have been established in cardiac surgery, liver transplantation and in major orthopedic procedures. Despite being the oldest agent used to reduce surgical bleeding, EACA has been poorly evaluated. The expected benefit of these agents is highly dependent on the actual blood usage for a given procedure at the institutional level. Further trials are required to determine optimal dosing. Comparative data on clinical efficacy are inconclusive to recommend an agent of choice. Rare thromboembolic complications have been reported with antifibrinolytics and aprotinin, but remain difficult to ascribe to these agents. Aprotinin has been studied more extensively, and the drug has several other, potentially beneficial properties. However, the clinical significance of related effects has not been established, the direct cost of the drug is higher, inconsistencies regarding its safety in coronary artery surgery, and antigenicity are a matter of concern. Recombinant activated factor VII is an interesting new drug in this field. While rFVIIa should emerge as a valuable rescue hemostatic tool when intractable bleeding associated with complex coagulopathy occurs, there is currently no evidence to support its prophylactic use in elective surgical patients.

\section{References}

1 Lanpacis A, Fergusson D. Drugs to minimize perioperative blood loss in cardiac surgery: meta-analyses using perioperative blood transfusion as the outcome. The International Study of Peri-operative Transfusion (ISPOT) Investigators. Anesth Analg 1997; 85: 125867.

2 Levi M, Crombeecke $M E$, de Jonge E, et al. Pharmacological strategies to decrease excessive blood loss in cardiac surgery: a meta-analysis of clinically relevant endpoints. Lancet 1999; 354: 1940-7.

3 Theroux MC, Corddry DH, Tietz AE, Miller F, Peoples $J D$, Kettrick RG. A study of desmopressin and blood loss during spinal fusion for neuromuscular scoliosis: a randomized, controlled, double-blinded study. Anesthesiology 1997; 87: 260-7.

4 Wong AY, Irwin MG, Hui TW, Fung SK, Fan ST, Ma $E S$. Desmopressin does not decrease blood loss and 
transfusion requirements in patients undergoing hepatectomy. Can J Anesth 2003; 50: 14-20.

5 Day JR, Punjabi PP, Randi AM, Haskard DO, Landis $R C$, Taylor KM. Clinical inhibition of the seven-transmembrane thrombin receptor (PARl) by intravenous aprotinin during cardiothoracic surgery. Circulation 2004; 110: 2597-600.

6 Coats T, Roberts I, Shakur H. Antifibrinolytic drugs for acute traumatic injury. Cochrane Database Syst Rev 2004; 4: CD004896.

7 Henry DA, Moxey AJ, Carless PA, et al. Anti-fibrinolytic use for minimising perioperative allogeneic blood transfusion. Cochrane Database Syst Rev 2001; 1: CD001886.

8 Marcel RJ, Stegall WC, Suit CT, et al. Continuous small-dose aprotinin controls fibrinolysis during orthotopic liver transplantation. Anesth Analg 1996; 82: 1122-5.

9 Garcia-Huete L, Domenech P, Sabate A, MartinezBrotons F, Jaurrieta E, Figueras J. The prophylactic effect of aprotinin on intraoperative bleeding in liver transplantation: a randomized clinical study. Hepatology 1997; 26: 1143-8.

10 Porte RJ, Molenaar IQ Begliomini B, et al. Aprotinin and transfusion requirements in orthotopic liver transplantation: a multicentre randomised double-blind study. EMSALT Study Group. Lancet 2000; 355: 1303-9.

11 Capdevila X, Calvet $\Upsilon$, Biboulet P, Biron C, Rubenovitch $J$, d'Athis $F$. Aprotinin decreases blood loss and homologous transfusions in patients undergoing major orthopedic surgery. Anesthesiology 1998; 88: $50-7$.

12 Samama CM, Langeron O, Rosencher N, et al. Aprotinin versus placebo in major orthopedic surgery: a randomized, double-blinded, dose-ranging study. Anesth Analg 2002; 95: 287-93.

13 Amar D, Grant FM, Zhang H, Boland PJ, Leung DH, Healey JA. Antifibrinolytic therapy and perioperative blood loss in cancer patients undergoing major orthopedic surgery. Anesthesiology 2003; 98: 337-42.

14 Beierlein W, Scheule AM, Antoniadis G, Braun C, Schosser $R$. An immediate, allergic skin reaction to aprotinin after reexposure to fibrin sealant. Transfusion 2000; 40: 302-5.

15 Dietrich W, Spath P, Zublsdorf M, et al. Anaphylactic reactions to aprotinin reexposure in cardiac surgery: relation to antiaprotinin immunoglobulin G and $\mathrm{E}$ antibodies. Anesthesiology 2001; 95: 64-71; discussion $5 \mathrm{~A}-6 \mathrm{~A}$.

16 Alderman EL, Levy JH, Rich JB, et al. Analyses of coronary graft patency after aprotinin use: results from the International Multicenter Aprotinin Graft Patency
Experience (IMAGE) trial. J Thorac Cardiovasc Surg 1998; 116: 716-30.

17 Frumento RJ, O'Malley CM, Bennett-Guerrero E. Stroke after cardiac surgery: a retrospective analysis of the effect of aprotinin dosing regimens. Ann Thorac Surg 2003; 75: 479-83; discussion 483-4.

18 Mangano DT, Tudor IC, Dietzel C; Multicenter Study of Perioperative Ischemia Research Group; Ischemia Research and Education Foundation. The risk associated with aprotinin in cardiac surgery. N Engl J Med 2006; 354: 353-65.

19 Molenaar IQ Begliomini B, Grazi GL, et al. The effect of aprotinin on renal function in orthotopic liver transplantation. Transplantation 2001; 71: 247-52.

20 Schweizer A, Hohn L, Morel DR, Kalagos A, Licker M. Aprotinin does not impair renal haemodynamics and function after cardiac surgery. Br J Anaesth 2000; 84: 16-22.

21 Kluger R, Olive DJ, Stewart AB, Blyth CM. Epsilonaminocaproic acid in coronary artery bypass graft surgery: preincision or postheparin? Anesthesiology 2003; 99: 1263-9.

22 Dowd NP, Karski JM, Cheng DC, et al. Pharmacokinetics of tranexamic acid during cardiopulmonary bypass. Anesthesiology 2002; 97: 390-9.

23 Fiechtner BK, Nuttall GA, Johnson ME, et al. Plasma tranexamic acid concentrations during cardiopulmonary bypass. Anesth Analg 2001; 92: 1131-6.

24 Kang $\Upsilon$, Lewis JH, Navalgund A, et al. Epsilon-aminocaproic acid for treatment of fibrinolysis during liver transplantation. Anesthesiology 1987; 66: 766-73.

25 Dalmau A, Sabate A, Acosta F, et al. Tranexamic acid reduces red cell transfusion better than epsilon- aminocaproic acid or placebo in liver transplantation. Anesth Analg 2000; 91: 29-34.

26 Boylan JF, Klinck JR, Sandler AN, et al. Tranexamic acid reduces blood loss, transfusion requirements, and coagulation factor use in primary orthotopic liver transplantation. Anesthesiology 1996; 85: 1043-8.

27 Kaspar M, Ramsay MA, Nguyen AT, Cogswell M, Hurst $G$, Ramsay KJ. Continuous small-dose tranexamic acid reduces fibrinolysis but not transfusion requirements during orthotopic liver transplantation. Anesth Analg 1997; 85: 281-5.

28 Hiippala ST, Strid LJ, Wennerstrand MI, et al. Tranexamic acid radically decreases blood loss and transfusions associated with total knee arthroplasty. Anesth Analg 1997; 84: 839-44.

29 Good L, Peterson E, Lisander B. Tranexamic acid decreases external blood loss but not hidden blood loss in total knee replacement. Br J Anaesth 2003; 90: 596-9.

30 Zohar E, Ellis M, Ifrach N, Stern A, Sapir O, Fredman 
$B$. The postoperative blood-sparing efficacy of oral versus intravenous tranexamic acid after total knee replacement. Anesth Analg 2004; 99: 1679-83.

31 Cid J, Lozano M. Tranexamic acid reduces allogeneic red cell transfusions in patients undergoing total knee arthroplasty: results of a meta-analysis of randomized controlled trials. Transfusion 2005; 45: 1302-7.

32 Sethna NF, Zurakowski D, Brustowicz RM, BacsikJ, Sullivan LJ, Shapiro F. Tranexamic acid reduces intraoperative blood loss in pediatric patients undergoing scoliosis surgery. Anesthesiology 2005; 102: 727-32.

33 Dentz ME, Slaughter TF, Mark JB. Early formation on heparin-bonded pulmonary artery catheters in patients receiving epsilon aminocaproic acid. Anesthesiology 1995; 82: 583-6.

34 Stafford-Smith M, Phillips-Bute B, Reddan DN, Black J, Newman MF. The association of epsilon-aminocaproic acid with postoperative decrease in creatinine clearance in 1502 coronary bypass patients. Anesth Analg 2000; 91: 1085-90.

35 Diprose P, Herbertson MJ, O’Shaughnessy D, Deakin $C D$, Gill RS. Reducing allogeneic transfusion in cardiac surgery: a randomized double-blind placebo-controlled trial of antifibrinolytic therapies used in addition to intra-operative cell salvage. Br J Anaesth 2005; 94: 271-8.

36 Dalman A, Sabate A, Koo M, et al. The prophylactic use of tranexamic acid and aprotinin in orthotopic liver transplantation: a comparative study. Liver Transpl 2004; 10: 279-84.

37 Roberts HR, Monroe DM 3rd, Hoffman M. Safety profile of recombinant factor VIIa. Semin Hematol 2004; 41(1 Suppl 1): 101-8.

38 Ghorashian S, Hunt BJ. "Off-license" use of recombinant activated factor VII. Blood Rev 2004; 18: 24559.

39 Dutton RP, McCunn M, Hyder M, et al. Factor VIIa for correction of traumatic coagulopathy. J Trauma 2004; 57: 709-19.

40 Boeblen F, Morales MA, Fontana P, Ricou B, Irion $O$, de Moerloose P. Prolonged treatment of massive postpartum haemorrhage with recombinant factor VIIa: case report and review of the literature. BJOG 2004; 111 : 284-7.

41 Boffard KD, Riou B, Warren B, et al; NovoSeven Trauma Study Group. Recombinant factor VIIa as adjunctive therapy for bleeding control in severely injured trauma patients: two parallel randomized, placebo-controlled, double-blind clinical trials. J Trauma 2005; 59: 8-15; discussion 15-8.

42 Friederich PW, Henny CP, Messelink EJ, et al. Effect of recombinant activated factor VII on perioperative blood loss in patients undergoing retropubic prostatec- tomy: a double-blind placebo-controlled randomised trial. Lancet $2003 ; 361: 201-5$.

43 Lodge JP, Jonas S, Jones RM, et al; rVIIa OLT Study Group. Efficacy and safety of repeated perioperative doses of recombinant factor VIIa in liver transplantation. Liver Transpl 2005; 11: 973-9.

44 Lodge JP, Jonas S, Oussoultzoglou E, et al. Recombinant coagulation factor VIIa in major liver resection: a randomized, placebo-controlled, double-blind clinical trial. Anesthesiology 2005; 102: 269-75.

45 Raobaikady R, Redman J, Ball JA, Maloney G, Grounds $R M$. Use of activated recombinant coagulation factor VII in patients undergoing reconstruction surgery for traumatic fracture of pelvis or pelvis and acetabulum: a double-blind, randomized, placebo-controlled trial. $\mathrm{Br}$ J Anaesth 2005; 94: 586-91. 